4 Dautzenberg B, Piperno D, Diot P, Truffot-Pernot C, Chauvin JP. Clarithromycin in the treatment of Mycobacterium avium lung infections in patients without AIDS. Clarithromycin Study Group of France. Chest 1995;107:1035-40

5 Roussel G, Igual J. Clarithromycin with minocycline and clofazimine for Mycobacterium avium intracellulare complex lung disease in patients without the acquired immune deficiency syndrome. GETIM. Groupe d'Etude et de Traitement des Infections a Mycobacteries. Int J Tuberc Lung Dis 1998;2:462-70

6 Uzun C, Koten M, Adali MK, Yorulmaz F, Yagiz R. Karasalihoglu AR. Reversible ototoxic effect of azithromycin and clarithromycin on transiently evoked otoacoustic emissions in guinea pigs. $J$ Laryngol Otol 2001;115:622-8

7 Kolkman W, Groeneveld JH, Baur HJ, Verschuur HP. Ototoxicity induced by clarithromycin [in Dutch]. Ned Tijdschr Geneeskd 2002;146:1743-5

8 Dokmeci I. Pharmacology: Basic concepts [in Turkish]. Istanbul: Nobel Tip Kitapevleri, 2000

9 Brummett RE. Ototoxic liability of erythromycin and analogues. Otolaryngol Clin North Am 1993;26:811-9

10 Dylewski J. Irreversible sensorineural hearing loss due to erythromycin. CMAJ 1988;139:230-1

11 Ress BD, Gross EM. Irreversible sensorineural hearing loss as a result of azithromycin ototoxicity. A case report. Ann Otol Rhinol Laryngol 2000;109:435-7

12 Levin G, Behrenth E. Irreversible ototoxic effect of erythromycin. Scand Audiol 1986;15:41-2

Cem Uzun, M.D.

Department of Oto-Rhino-Laryngology, Head and Neck Surgery,

Trakya University,

Faculty of Medicine,

Edirne, Turkey.

\section{Cholesterol granuloma of the frontal sinus}

$J L O$ 2002;116:1041-4

Dear Sirs,

We read with interest the case report by Shykhon et $a l$. on Cholesterol granuloma of the frontal sinus. ${ }^{1}$ Cholesterol granuloma is indeed far less commonly found in the paranasal sinuses that the temporal bone, with the frontal sinus being less frequently affected than the maxillary sinus. Our own unpublished series of five frontal sinus cholesterol granulomas over a ten-year period in a specialist Rhinology unit reflects the rarity of this condition. As the paper indicates, most of the literature on the subject concerns the petrous temporal bone, or, in the para-nasal sinuses, the maxillary sinus. It is of significance, however, that while the authors state "few cases have been reported" in the frontal sinus, they fail to cite any of the publications reporting this condition in the medical literature, including a previous article in the Journal of Laryngology and Otology. ${ }^{2}$

The lesion, which may follow a history of trauma, originates within the diploe of the frontal bone from where it expands extra-periosteally around the orbit. It is not surprising therefore that affected patients usually present to an Ophthalmologist. Our Medline search on cholesterol granuloma of the frontal sinus from 1974 to 2002 identified that the largest published series was from Moorfields Eye Hospital, who described 27 cases of orbito-frontal cholesterol granuloma seen between 1967 and $1988 .{ }^{3}$ All but one of the patients presented with expansion of the lesion into the extra-periosteal space in the region of the lacrimal fossa. Six of the 29 patients had a history of trauma to the area and the authors suggested that haemorrhage into the diploe of the frontal bone was the most likely cause. All patients were cured by extra-periosteal drainage. The radiological findings of 31 patients from the same unit from 1974 to 1991 were published in $1992 .{ }^{4}$ All patients had been investigated by plain X-ray, 21 underwent CT imaging and one patient an MRI study. The typical CT findings of ragged bony destruction with a soft tissue mass no more dense than brain extending extra-periosteally into the orbit are discussed, together with the findings of high signal intensity on both the T1 and T2 images of the MRI scan. Very similar radiological findings were described in a report of 11 patients from Holland. ${ }^{5}$

Our Midline literature search on 'cholesterol granuloma' from 1966 to the present day identified 421 reports in total, 30 of which detailed the clinical, pathological or radiological features of between one and 31 patients with disease in the orbito-frontal region. The condition is clearly not as rarely reported as Shykhon et al. suggest and we feel that their paper would have benefited from a more comprehensive assessment of the current literature than was evidently performed.

Natalie Brookes

Specialist Registrar

Valerie Lund

Professor of Rhinology

Institute of Laryngology and Otology

Royal National Throat, Nose \& Ear Hospital, London

\section{References}

1 Shykhon SE, Trotter MI, Morgan DW, Reuser TTQ, Henderson MJ. Cholesterol granuloma of the frontal sinus. J Laryngol Otol 2002;116:1041-3

2 Butler S, Grossenbacher R. Cholesterol granuloma of the paranasal sinuses. J Laryngol Otol 1989;103:776-9

$3 \mathrm{McNab}$ AA, Wright JE. Orbitofrontal cholesterol granuloma. Ophthalmology 1990;97:28-32

4 Rowland Hill CA, Moseley IF. Imaging of orbitofrontal cholesterol granuloma. Clin Radiol 1992;46:237-42

5 Eijpe AA, Koornneef L, Verbeeten B Jr, Peeters FL, Zonneveld FW. Cholesterol granuloma of the frontal bone: CT diagnosis. J Comput Assist Tomogr 1990;14:914-7

Analytical and clinical evaluation of CYFRA 21-1 by electrochemiluminescent immunoassay in head and neck squamous cell carcinoma. $J L O$ 2003;117:190-4

Dear Sirs,

While we took note of the investigation performed by Deng et al. ${ }^{1}$ with great interest, we would like to state the following comments:

The clinical importance of the Cyfra 21-1 serum concentration as tumour marker in patients with squamous cell carcinomas of the head and neck has been described previously. ${ }^{2-4}$ In a recent publication $^{4}$ the Cyfra 21-1 serum concentration is evaluated by means of an ELISA test kit. Deng 